\title{
Synthesis of Important Design Criteria for Future Vehicle Electric System
}

\author{
Lisa Braun ${ }^{\text {1 }} 1$, Eric Sax ${ }^{2}$
}

${ }^{1}$ Ph.D. Candidate, Institute for Information Processing Technologies, Karlsruhe Institute of Technology, Germany

${ }^{2}$ Professor, Institute for Information Processing Technologies, Karlsruhe Institute of Technology, Germany

\begin{abstract}
A B S T R A C T In this article, we give a brief overview of future trends and corresponding stakeholder requests regarding the design of automotive electric and electronic (e/e)-architectures. While today's optimization is mainly based on the static design criteria of unit costs and weight, three dynamic design criteria are considered decisive factors in the future: voltage stability, vehicle energy consumption and total cost of ownership. It is shown, how quantitative values for each criterion can be derived, on basis of which different designs of a potential future power supply system could be evaluated. Subsequently, their potential influences on the future system design is discussed.
\end{abstract}

\section{Introduction}

This paper is an extension of work originally presented in the 4th International Conference on Electrical Systems for Aircraft, Railway, Ship propulsion and Road Vehicles and International Transportation Electrification Conference [1]. The focus of [1] is to summarize the results of guided expert interviews on future trends, associated hurdles and requirements of the electric and electronic (e/e)-architecture.

The design of the e/e-architecture of vehicles faces many challenges. The information and communication system has to manage and distribute an amount of data that is rapidly growing due to digitization and new functionalities, while the energy distribution system has to provide sufficient energy to securely supply the growing number of electrical components. This growing number of components, functions and connections makes system complexity ever-increasing [1]. This also means that development expenditures are growing significantly. Over $40 \%$ of the development expenses of a luxury vehicle is related to e/e [2].

The expert interviews were designed to find out which trends the e/e-architecture will shape in the future, and whether and how the design criteria for development will change. Considering these results, we are expanding our work by synthesizing design criteria that will be important in the future, focusing on the power supply system as part of the e/earchitecture. These criteria are based on the trends and the overview given in [1]. We also discuss the effects of such a change in design criteria on the development of vehicles, and in particular the design of the energy distribution system in the future.

This paper is organized as follows: section two discusses current trends concerning the e/e architecture. Section three summarizes important stakeholder requests on the design of e/e-architectures. While design criteria that are considered important for future power supply systems are synthesised in section four. Examples show their possible impact on design. Subsequently section 5 discusses their influence on future system design. The final section shows conclusions and future works.

\section{Trends Concerning the Vehicle Electric System}

Today, autonomous driving is one of the most important trends in the automotive industry. Last year, the number of companies testing autonomous vehicles in California doubled. By March 2017, 27 companies received Autonomous Vehicle Testing Permits from California Department of Motor Vehicles.

What is more, in recent years, a change in the mobility behaviour can be observed in all the countries of the Triad [3]. In 2015, the number of registered car sharing users in Germany amounted to 1.26 million already, equating to a six-fold increase since 2011

${ }^{*}$ Lisa Braun, lisa.braun@partner.kit.edu 
[4]. This strong growth might even be reinforced even more by the introduction of autonomous vehicles. A possible combination of apps like SMILE, GoogleNow, and e-hailing with autonomous vehicles promises to create ideal robot taxis as part of a multimodal mobility concept to implement mobility as a service [5].

To allow autonomous manoeuvres, an exact environment model and thus a large number of sensors for environment detection on board the vehicle are necessary. Moreover, networking with other vehicles and the infrastructure is a precondition to avoid dangers on the route [1]. Both lead to yet another significant increase in the amount of data on board [6]. In addition, they must not fail during driving in order to ensure safe operation of the vehicle. Therefore, the power supply needs to provide at least two independent sources, so that the supply of these safetyrelevant components is at no time endangered.

To allow for the provision of this growing power demand, a multi voltage power supply is seen as certain. With the $12 \mathrm{~V}$ electrical system limited to $3.6 \mathrm{~kW}$ maximum power, it became increasingly difficult to provide the growing power demand of new functions such as active roll stabilization (ARS) [7]. The introduction of an additional $48 \mathrm{~V}$ level shall solve that problem [8].

Further, it is cheaper as high-voltage systems in hybrid vehicles as it is still below $60 \mathrm{~V}$, which means no additional isolation is necessary. The higher voltage also allows a reduction of cable cross sections while the efficiency of the distribution increases. The weight of the cable harness could be further reduced by using semiconductors instead of fuses and relays [9].

\section{Stakeholder Requests}

About $90 \%$ of the surveyed experts mention costs as an important design feature of the established e/earchitecture, followed by $80 \%$ naming weight. Thus, these two criteria are clearly mentioned most frequently, see also Figure 1 [1].

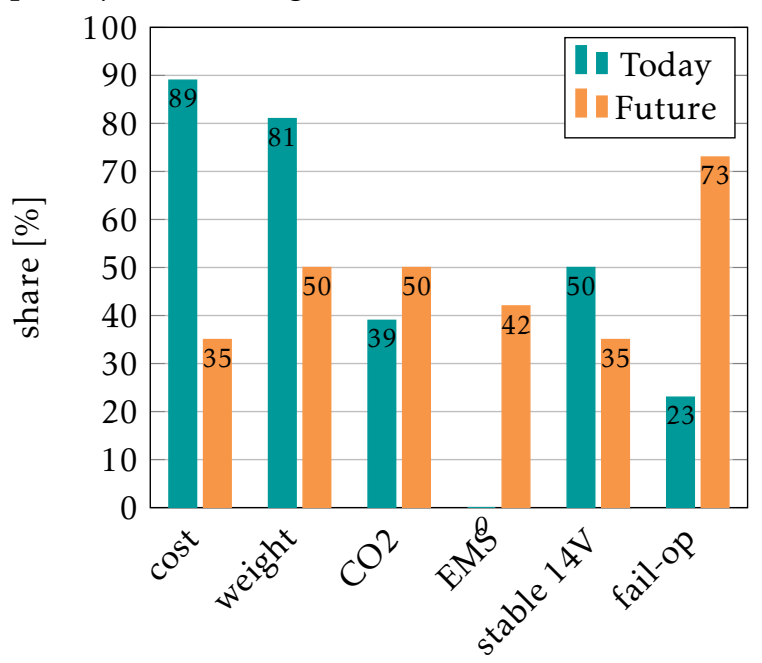

Figure 1 Significance of today's and future requirements concerning the e/e-architecture.
Concerning future design criteria, however, this picture changes. While the importance of cost and weight sink to $35 \%$ and $50 \%$, over $73 \%$ of the experts think a fail-operational design is important. Another criterion for safe operation, the stability of the voltage, is considered important in future design by at least one third of the experts. The reference to the reduction of carbon emissions increases from 39\% to $50 \%$. In addition, about $40 \%$ of the experts are asking for an energy management system (EMS) for the future, while it does not seem to matter at all [1].

The focus on fail-operational is due to current developments in driver assistance with the aim of integrating autonomous driving. Failures are not acceptable and must therefore be prevented by a corresponding design of the system, mostly realized by redundancy mechanisms. An example how this could be realized for the information and communication architecture is the developed centralized platform computer of the RACE project [10]. A fail-operational power supply is realized through at least two independent power sources [11]. While this applies to an electric vehicle with DC/DC-converter and one battery in the low-voltage network, sailing with switched off combustion engine or start-stop mode would lead to a system with only one source, if only one battery is installed additionally to the generator [7].

What is more is that voltage stability must be guaranteed even with fast load changes and high power peaks. An EMS could therefore contribute to the stabilization of the voltage as well as the reduction of the consumption and associated emissions.

However, the experts' answers do not allow any conclusion as to whether these changes in the values are due to actual changes in the prioritization or due to the current trends and associated expected future problems. In the case of costs in particular, it seems questionable whether their significance in the future will actually decrease so clearly. Nevertheless, these figures allow conclusions to be drawn on expected changes in the development. In the following, important future design criteria of the power supply system are derived from this selection.

\section{Synthesis of Important Design Criteria}

Not technical aspects are the main problem for achieving future solutions but legacy restrictions and fixed corporate structures, which go along with the structure of the vehicle's e/e-architecture [1]. Design criteria that consider future changes can help to weigh up possible solutions in the early stages of development. Therefore, the aim of the derived design parameters is to provide the advantages and disadvantages of the various designs of the power supply system even in an early development phase. For this reason, they must provide measurable target variables, with the aid of which different designs can be evaluated and an optimal solution can be derived. 
Firstly, to guarantee the safe operation the voltage stability must be guaranteed. This is an essential constraint for the integration of safety-relevant functions. Although fail-operational is of great importance for the design of future e/e-architectures due to the results in [1], no corresponding evaluation criterion is developed in the following. In addition to the requirement of a redundant power source, an isolated view of the power supply system does not seem to make sense. Rather, an intelligent combination of measures in the communication and power supply network can save required redundancy effort, e.g. through a combination of powerline communication and power over dataline for safety-relevant components [12].

Secondly, at the latest since the diesel-gate, vehicle emissions have been the focus of attention. Weight reduction as well as higher efficiency of the power distribution or reduction of the power consumption e.g. through EMS can help to reduce the energy consumption of the vehicle as well as the corresponding emissions. There is a conflict, however, between a light weight wire harness with small cable cross-sections and the achievement of minimal power losses through the distribution, as small cross-sections increase the cable resistance. In order to find an optimum compromise, the vehicle consumption is therefore chosen as a further design criterion.

Finally, today the costs per function must be minimal. We expect this to change in the future due to the growing volume of car sharing and stricter emission limits. Operators of car sharing fleets are less interested in the purchasing prize than in the total cost of ownership. Simultaneously, the operating time and thus the influence of the travel costs on the total cost of ownership increases. For this reason, not only development and production costs but also operating costs must be taken into account in minimizing costs in the future.

\subsection{Voltage Stability}

For safe operation of e/e-systems, it is important that the voltage limits of $11 \mathrm{~V}$ and $16 \mathrm{~V}$ are maintained at the sinks, otherwise the functionality is not, or only partially, provided. Via the buffer of the voltage to these limits, for example, in an extreme driving scenario, it is possible to compare different configurations of the power supply system [13].

The disadvantage of this method is that it does not provide any information about the temporal behaviour of the voltage. The minimally determined value could be anything between an outreach and a constant curve or a broadband noise within the determined range.

Conclusions on the scattering can, for example, be drawn with the so-called quantiles. This is a method of statistics in which an ordered data series is split into two equal halves by the median. The box plot can thus be formed over the interquartile distance between the $25 \%$ quantile and the $75 \%$ quantile. The median indicates which voltage level the curve varies, and the size of the box between the $25 \%$ value and the $75 \%$ value shows how strong this variation is.

Alternatively, the standard deviation $s$ based on the empirical variance $\sigma$ can be used as a further method of statistics for evaluation. It indicates the average deviation of the measured values $x_{i}$ from the mean value $\bar{x}$ of $\mathrm{n}$ data points. The smaller the standard deviation, the more stable is the curve of the voltage for the observed time interval. The standard deviation is calculated as follows [14]:

$$
\mathrm{s}=\sqrt{\sigma(x)}=\sqrt{\frac{\sum_{i=1}^{n}\left(x_{i}-\bar{x}\right)^{2}}{n}}
$$

Figure 2 shows voltage curves with varying volatility. The blue curve shows a strong fluctuation around $12 \mathrm{~V}$. The green curve fluctuates considerably less by $14 \mathrm{~V}$. The orange curve includes a voltage jump after 300s. Before the jump, it is comparatively stable at $11 \mathrm{~V}$, then stable at $14 \mathrm{~V}$. Figure 3 shows that for the blue and green curves the fluctuation and its corresponding voltage level can be represented well with the box plot. However, the jump of the orange curve is not evaluated correctly. The values before the jump are considered as outreach and therefore this curve appears incorrectly as the most stable.

If the mean value is replaced by the system voltage of $14.3 \mathrm{~V}$ the standard deviation in figure 4 can as well consider the voltage level in the evaluation. Figure 4 shows that the standard deviation, in contrast to the box plot, correctly reflects the stability of the voltages in figure 2 and the green voltage curve is correctly recognized as the most stable followed by the orange. Therefore, the standard deviation appears to be a suitable parameter to evaluate voltage stability.

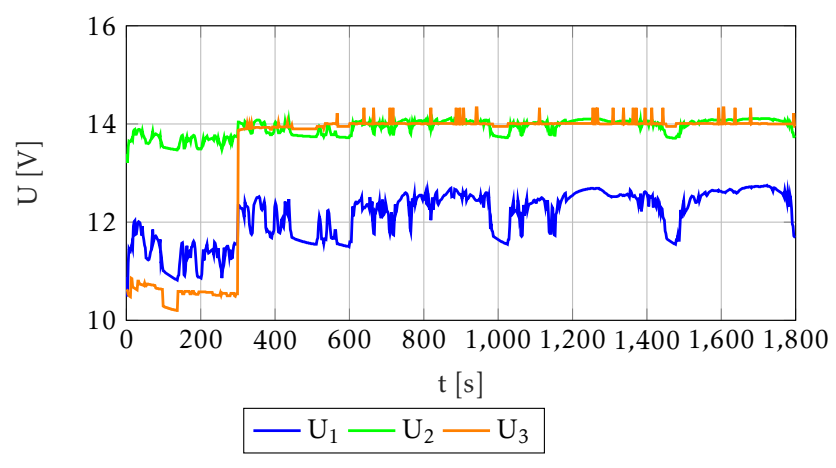

Figure 2 Voltage curves with variing volatility.

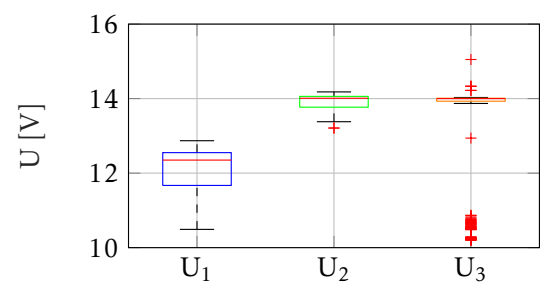

Figure 3 Box plots of shown voltage curves. 


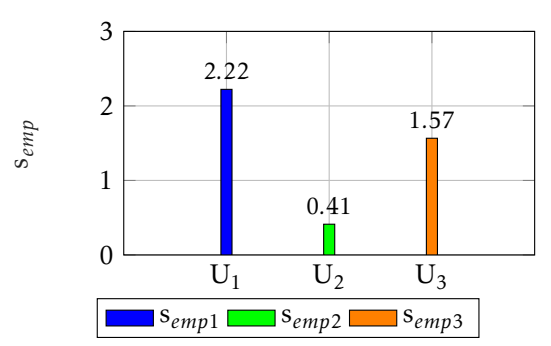

Figure 4 Standard deviation of shown voltage curves.

\subsection{Vehicle Energy Consumption}

In Europe, the allowed $\mathrm{CO}_{2}$-emissions will be reduced to $95 \frac{\mathrm{gCO}}{\mathrm{km}}$ by 2020 , while the full fines will reach $95 \frac{€}{\mathrm{~g}}$ from 2019 onward [15]. What makes it even more difficult is the fact that from 2020 onwards a new test method with a realistic driving cycle, the Worldwide harmonized Light duty driving Test Cycle (WLTC), for the determination of the emissions takes effect. It is expected that the discrepancy between the actual consumption and the calculated standard values will drop from an average of about $45 \%$ in 2015 to $23 \%$ in 2020 [16]. Conversely, this means that if the actual consumption is constant, the measured standard emissions are increased by $22 \%$.

One reason for this is the fact that the consumption optimization of the vehicles to the unrealistic, static speed profile of the previous New European Driving Cycle (NEDC), no longer takes effect. Without the untypically high dead times and frequent stops, the previous high influence of consumptionreducing measures such as start-stop-automatic and downsizing is reduced [17]. Other factors such as weight reduction and the reduction of transmission losses in the power supply network are instead brought into the focus.

The specific vehicle consumption $\mathrm{B}_{s V}$ per $100 \mathrm{~km}$ can be calculated as a function of the distance travelled $s_{c}$ and the needed propulsion energy $\mathrm{W}_{\text {pro }}$ and recuperation energy $\mathrm{W}_{\text {rek }}$. If no recuperation is integrated, $\mathrm{W}_{\text {rek }}$ is zero.

$$
B_{s V}=\left(W_{\text {pro }}+W_{r e k}\right) \cdot \frac{100}{s_{c}}
$$

The energy required by the propulsion or the recuperation energy which may be fed back depends of the energy requirement $\mathrm{W}_{c}$ on the tires. It depends on the total drive resistor $\mathrm{F}_{t}$ and the travelled distance $s_{c}$ which can be derived from the velocity profile $v_{c}$ of the drive cycle.

$$
W_{c}=F_{t} \cdot s_{c}=F_{t} \cdot \int_{0}^{t} v_{c}(\tau) \mathrm{d} \tau .
$$

In addition to the time profile of the energy requirement on the wheels during the cycle, the energy required by the propulsion or the recuperation energy to be fed back depends on the efficiency $\eta_{d t}$ of the drive train.

$$
\begin{array}{ll}
W_{\text {pro }}=\int_{0}^{t} \frac{1}{\eta_{d t}(\tau)} \cdot F_{t}(\tau) \cdot s_{c}(\tau) \mathrm{d} \tau & \text { for }\left(F_{a}>0\right) \\
W_{\text {rek }}=\int_{0}^{t} \eta_{d t}(\tau) \cdot F_{t}(\tau) \cdot s_{c}(\tau) \mathrm{d} \tau & \text { for }\left(F_{a}<0\right) .
\end{array}
$$

The total drive resistance $\mathrm{F}_{t}$ is composed of several values: the rolling resistance $\mathrm{F}_{r}$, the slope resistance $\mathrm{F}_{s}$, the air resistance $\mathrm{F}_{l}$ and the acceleration resistance $\mathrm{F}_{a}$ which are calculated as follows [18]:

$$
\begin{aligned}
& F_{t}=F_{r}\left(m_{v e h}\right)+F_{s}\left(m_{v e h}\right)+F_{l}\left(v_{c}(t)\right)+F_{a}\left(m_{v e h}, a(t)\right) \\
& F_{r}=m_{v e h} \cdot g \cdot c_{r} \\
& F_{s}=m_{v e h} \cdot g \cdot \sin (\beta(t)) \\
& F_{l}=\frac{1}{2} \cdot \rho_{l} \cdot c_{W} \cdot A_{v e h} \cdot v_{c}(t)^{2} \\
& F_{a}=F_{a . t r a n s}+F_{a, \text { rot }}=a(t) \cdot\left(m_{v e h}+\frac{J_{W h}+i^{2} \cdot J_{E n}}{r_{s t a t} \cdot r_{d y n}}\right)
\end{aligned}
$$

The rolling resistance $\mathrm{F}_{r}$ and the slope resistance $\mathrm{F}_{s}$ depend on the vehicle weight $\mathrm{m}_{v e h}$ and the gravity g. The coefficient $c_{r}$ takes into account the walk losses which occur on the road. $\beta$ indicates the slope angle of the street. The air resistance $\mathrm{F}_{l}$ is calculated from the front surface $\mathrm{A}_{v e h}$, the air density $\rho_{l}$, the air drag coefficient $\mathrm{c}_{W}$, and the air inflow velocity $v_{c}(\mathrm{t})$ of the vehicle. The resistance $\mathrm{F}_{a}$, which is dependent on the acceleration $a$, consists of a weight-dependent translatory part and a rotational part. The latter depends on the moment of inertia of the wheels $\mathrm{J}_{W h}$ and engine $\mathrm{J}_{E n}$, the translation $i$ and the static $\mathrm{r}_{\text {stat }}$ and dynamic $\mathrm{r}_{d y n}$ free radius.

The energy consumption of the electrical components and the power distribution $\mathrm{W}_{E}$ can be determined either by measurement in a test stand or, especially in early development phases, by means of a model-based analysis. In both cases, an operating model of the loads $P_{i}(t)$ is required to determine the energy consumption, as it fixes the current flow and thus the losses $\mathrm{P}_{V, d s t}(t)$ during transmission. What is more, in a vehicle with an internal combustion engine (ICE), the efficiency of the drive $\eta_{d}$ and the efficiency of the generator $\eta_{g}$ must be considered. In the case of an electric vehicle, this would instead be the efficiency of the high voltage battery and the DC/DC-converter. In order to determine the specific consumption $\mathrm{B}_{S E}$, the values have to be converted to a distance of $100 \mathrm{~km}$ analogous to the driving consumption

$$
\begin{aligned}
W_{E} & =\int_{0}^{t} \frac{1}{\eta_{d}(\tau) \cdot \eta_{g}(\tau)} \cdot\left(\sum_{i=1}^{n} P_{i}(\tau)+P_{V, d s t}(\tau)\right) \mathrm{d} \tau \\
B_{S E} & =W_{E} \cdot \frac{100}{s_{c}}
\end{aligned}
$$

The sum of both specific consumption values provides the total consumption of the vehicle, which is to be optimized. 
Table 1 Vehicle data of a small car (A), a SUV (J) and an electric luxury car (F).

\begin{tabular}{lllll}
\hline \hline Parameter & unit & $\mathrm{A}$ & $\mathrm{J}$ & $\mathrm{F}$ \\
\hline propulsion & & $\mathrm{ICE}$ & $\mathrm{ICE}$ & electric \\
\hline weight & {$[\mathrm{kg}]$} & 885 & 2,435 & 2,000 \\
\hline $\begin{array}{l}\text { standard } \\
\text { consumption }\end{array}$ & {$\left[\frac{\mathrm{kWh}}{100 \mathrm{~km}}\right]$} & $\begin{array}{l}38.7 \\
(=4.5 l)\end{array}$ & $\begin{array}{l}80.84 \\
(=9.4 l)\end{array}$ & 22.04 \\
\hline $\begin{array}{c}\text { standard } \\
\text { emission }\end{array}$ & {$\left[\frac{g C \mathrm{CO}_{2}}{\mathrm{~km}}\right]$} & 93 & 218 & 0 \\
\hline \hline
\end{tabular}

The given standard values in table 1 are measured with the established New European Driving Cycle (NEDC). Assuming that both ICE-vehicles would be $50 \mathrm{~kg}$ lighter, the power consumption per $100 \mathrm{~km}$ of the small car could be reduced by $0.89 \mathrm{kWh}$ and the standard emissions by $2.4 \mathrm{~g}$. For the SUV, the consumption would drop by $0.91 \mathrm{kWh}$ which would lead to $2.45 \mathrm{~g}$ less emission per $\mathrm{km}$. In comparison, the high efficiency of the electric drive train with $3.71 \mathrm{kWh}$ enables a significantly higher reduction in consumption by weight reduction. These values are calculated in MATLAB with the given equations (2) to (10) and the cycle data of the NEDC.

To calculate the equivalent electrical energy consumption during the NEDC, an average speed of $33.6 \frac{\mathrm{km}}{\mathrm{h}}$ is assumed. It is further assumed that the efficiency of the ICE is $35 \%$, the efficiency of the generator is $75 \%$, while the efficiency of the high-voltage battery and the DC/DC-converter is $95 \%$. Under these circumstances a reduced electrical energy consumption of $78 \mathrm{~W}$ for the small car, $80 \mathrm{~W}$ for the SUV and $1125 \mathrm{~W}$ for the electric car would have the same effect.

\subsection{Total Cost of Ownership}

Since, on the one hand, the permissible emission limit values $\mathrm{G}_{\mathrm{CO}_{2}, 0}$ fall, and on the other hand, higher standard values are to be expected by the more realistic determination in the future, the deviating development costs of alternative designs are estimated with the help of $\mathrm{CO}_{2}$-emission penalties.

The allowed emission limit $\mathrm{G}_{\mathrm{CO}_{2}}$ of a vehicle is calculated depending on its weight $\mathrm{m}_{v e h}$ and the weight correction factor $\mathrm{m}_{0}$ [15]:

$$
G_{\mathrm{CO}_{2}}=G_{\mathrm{CO}_{2}, 0}+0.0457 \cdot\left(m_{v e h}-m_{0}\right) .
$$

For each automobile manufacturer its fleet limit value is calculated with the individual emission limit of their different vehicle models and their sales figures. If the fleet emission exceeds this value, a penalty of $€ 95$ will be due for each gram from 2019 onwards.

The production costs can be estimated from the sum of the material costs of the power supply system. Furthermore, the operating costs can be determined from the specific driving consumption and the respective energy costs of the vehicle. Taxes for petrol vehicles in Germany are also dependent on the specific $\mathrm{CO}_{2}$-emissions and the engine displacement of the vehicle.
Table 2 Emission penalties and annual travel costs of the example vehicles at a running distance of $36,500 \mathrm{~km}$ a year.

\begin{tabular}{lllll}
\hline \hline Parameter & unit & $\mathrm{A}$ & $\mathrm{J}$ & $\mathrm{F}$ \\
\hline propulsion & & $\mathrm{ICE}$ & $\mathrm{ICE}$ & electric \\
\hline $\begin{array}{l}\text { allowed } \\
\text { emission limit }\end{array}$ & {$\left[\frac{g C \mathrm{gO}_{2}}{\mathrm{~km}}\right]$} & 72.74 & 143.58 & 123.7 \\
\hline $\begin{array}{l}\text { emission } \\
\text { penalty per } \\
\text { car in 2019 }\end{array}$ & {$[€]$} & 1,735 & 7,070 & 0 \\
\hline cost energy & {$\left[\frac{€}{\mathrm{kWh}}\right]$} & 0.1605 & 0.1605 & 0.2869 \\
\hline specific cost & {$\left[\frac{€}{100 \mathrm{~km}}\right]$} & 6.21 & 12.97 & 6.32 \\
\hline $\begin{array}{l}\text { Travel } \\
\text { expenses per } \\
\text { year }\end{array}$ & {$\left[\frac{€}{a}\right]$} & 2,267 & 4,736 & 2,308 \\
\hline $\begin{array}{l}\text { taxes } \\
\text { (Germany) }\end{array}$ & {$\left[\frac{€}{a}\right]$} & 198 & 496 & 0 \\
\hline \hline
\end{tabular}

Table 2 shows the associated costs of the three vehicles given in table 1 . First of all, table 2 shows that considering the weight correction factor of 1,372 of the year 2016, the emission limit of $95 \mathrm{gCO}_{2}$ per $\mathrm{km}$, and today's standard emission, both vehicles with internal combustion engine are significantly above the emission limit. Considering the new test procedure mentioned above, the high penalty per sold vehicle could rise even further. The annual taxes calculated in Germany are also dependent on $\mathrm{CO}_{2}$-emissions and therefore are the highest for the SUV.

For the comparison of different alternatives of the power supply network, an additional statistical calculation of the service costs is dispensed with since it is assumed that due to the low failure rates of electrical systems these will be similar for all alternatives.

\section{Influence on Future System De- sign}

While existing evaluation criteria such as unit costs and weight are static and can therefore be determined directly from the system design [19], all design criteria defined here depend on the dynamic operation of the vehicle and the electrical loads. Consequently, an operational model is essential for the determination of these criteria.

In order to evaluate the stability of the voltage, a worst-case scenario appears to be fitting, as is currently used when designing the energy source. However, for an accurate determination of the energy consumption and operating costs, the operation has to be taken into account over a longer period of time, as the ambient conditions such as light, weather and temperature change substantially over the course of a year and thus the use of the electrical loads varies. The created operating models of the loads must allow to adjust the environmental conditions, the route, and the driver in order to simulate the energy consumption of 
the electrical network in a realistic manner.

In the established determination of the standard consumption, electrical loads are switched off if possible. Thus, they are not considered when measuring the standard consumption and emission.

If for the implementation of safety, critical functions voltage stability is an indispensable constraint, it must be fulfilled at all costs. In particular, in the case of speed-dependent power generation in a combustion vehicle, a minimum battery capacity is required to maintain the voltage limits at all times. The standard deviation allows to evaluate different designs. It can for example be used to define a maximum allowed deviation value for a design to be considered stable. If a stable architecture is to be selected, designs with high storage capacity are preferred. Considering the fail-operational request for a redundant power source for internal combustion vehicles, the power supply network will likely contain at least two batteries independent of the other design criteria. In addition, bus or ring topologies are preferable to the existing star topology since these allow a simple distribution of the energy sources in the network in order, for example, to ensure the supply of the components in the event of a fault in the supply line [20].

The defined cost analysis also shows that the unit costs over the emission penalty as well as the operating costs depend on the consumption and consequently on the energy efficiency of a vehicle. Consequently, future architectures follow a trade-off between an energy-efficient design and small unit cost. A reduction of the consumption of the energy supply system by $200 \mathrm{~W}$ of the SUV discussed in the previous section by means of a system more expensive by $€ 570$ would be cost neutral due to the $6 \mathrm{~g}$ lower emissions and therefore reduced penalties. But an equivalent reduction of the emission by a weight reduction of $125 \mathrm{~kg}$ would only result in a reduction of the penalties by $€ 50$, since the permissible emission limit also drops to $138.1 \mathrm{gCO}_{2}$ per $\mathrm{km}$.

This shows that in this combination of evaluation criteria the optimization of the efficiency of the energy distribution is preferred to the optimization of the weight. In contrast, in the case of an electric vehicle, the optimization of the weight has a greater effect on the consumption, because of the high efficiency levels in the supply of the electrical network as well as the drive train. To minimize the operating costs, it does not matter how the reduction of the energy consumption is realized.

In summary, a redesign of the established power supply system to reduce the power consumption would not only lead to lower operating costs, but could also reduce the product price of ICE vehicles. In contrast to of today's cost optimization, higher costs per function through higher development or production costs might be acceptable as long the saved emission penalty costs are even or higher. These assessment criteria therefore call into question the established optimization approaches of the cable harness based on unit costs and weight.
Today, the introduction of a power bus with semiconductor switches instead of existing fuses in established vehicle models seems to be economically unprofitable due to the high development and material costs. If, however, the design criteria determined here are applied, the additional costs associated with the introduction would be acceptable if weight or efficiency savings in the electrical grid lead to equal or higher savings in emission penalties.

\section{Conclusion}

Electrification and digitalisation combined with new functions challenge the established e/e-architecture. Hence, it must change to meet future requirements. To be able to compare different alternatives of the power supply network, important design criteria are derived from prioritized stakeholder requests, taking into account the trends identified.

The stability of the voltage is an important boundary condition for the increasing integration of safetyrelevant components into the vehicle. It is shown that using the standard deviation not only the voltage limits, but the temporal fluctuations in the assessment of the voltage stability of different design alternatives can be considered. This allows to evaluate different designs concerning their expected stability.

Moreover, consideration of the energy consumption of the whole vehicle allows to find an optimum compromise between minimal weight and minimal electrical losses. On the one hand, the energy consumption of the vehicle combined with the usual energy costs of the different drive alternatives determine the specific operating costs. On the other hand, the energy consumption will significantly influence the selling price of a vehicle in the future by means of the emission penalties if the emission limit values are exceeded. This means that higher development or production costs for a redesign of the established power supply system are acceptable as long as they are equal or below the saved penalty costs. An additional bonus is that a higher efficiency lead to lesser operating costs which are of high importance for fleet vehicles e.g. for car sharing especially.

Since a weight reduction also reduces the permissible emission limit values of a vehicle, an equivalent reduction of the emission over a more efficient energy distribution system has a higher effect on the penalty savings. Therefore, the found optimization criteria call into question the established optimization approaches of the cable harness based mostly on unit costs and weight.

In future research, we will investigate the extent to which different freedoms in shaping the energy network can influence and facilitate the fulfillment of these criteria. For this purpose, a modelling environment in MATLAB/SIMULINK is created, which allows to examine alternative designs of the power supply network with regard to the dynamic design criteria defined here and to derive optimal combinations. 


\section{References}

[1] L. Braun, M. Armbruster, E. Sax, "Stakeholder Issues Concerning the Automotive E/EArchitecture" in 4th International Conference on Electrical Systems for Aircraft, Railway, Ship propulsion and Road Vehicles and International Transportation Electrification Conference, Toulouse France, 2016.

[2] E. Frank, R. Wilhelm, R. Ernst, A. SangiovanniVincentelli, M. Di Natale, "Methods, Tools and Standards for the Analysis, Evaluation and Design of Modern Automotive Architectures" in Design, Automation and Test in Europe, 659-663, 2008.

[3] W. Schade, C. Zanker, A. Kuehn, S. Kinkel, A. Jaeger, T. Hettesheimer, T. Schmall, "Zukunft der Automobilindustrie", Buero fuer TechnikfolgenAbschaetzung beim deutschen Bundestag, AB152 (working report), 2012.

[4] Bundesverband CarSharing, "CarSharingJahresbilanz 2015: Wachstum und Konsolidierung im deutschen CarSharing-Markt", press release, 29.02.2016

[5] F.-J. van Audenhove, L. Dauby, O. Korniichuk, J. Pourbaix. "The Future of Urban Mobility 2.0: Imperatives to shape extended mobility ecosystems of tomorrow", Arthur D Little and UITP, 2014.

[6] M. Klauda, M. Schaffert, A. Lagospiris, G. Piel, S. Kappel, and M. Ihle, "Position of Points 2020 Paradigm Shift in E/E Architectures", ATZ Elektron Worldw, 10(02), 4-11, 2015.

[7] L. Braun, M. Armbruster, F. Gauterin, "Trends in vehicle electric system design: State-of-the Art Summary" in Vehicular Power and Propulsion Conference, Montreal Canada, 2015.

[8] T. Doersam, S. Kehl, A. Klinging, A. Radon, O. Sirch, "The New Voltage Level - $48 \mathrm{~V}$ for Vehicle Power Supply", ATZ Elektron Worldw, 7(01), 1015, 2012.

[9] A. Graf, J. Kositza, T. Raithel, "Leading Edge Automotive Power Distribution", ATZelektronik wordlwide 8(03), 14-17, 2013.

[10] S. Sommer, A. Camek, K. Becker, C. Buckl, A. Zirkler, L. Fiege, M. Armbruster, G. Spiegelberg, A. Knoll, "RACE: A Centralized Platform Computer Based Architecture for Automotive Applications", in International Electric Vehicle Conference, Santa Clara CA USA, 2013.
[11] G. Weiss, P. Schleiss, C. Drabek "Fail-operational E/E Architecture for Highly-automated Driving Functions", ATZ Elektron Worldw 11(03), 16-21, 2016.

[12] W. Langhoff, M. Ernst, "Living wiring system bionics as a model for $\mathrm{E} / \mathrm{E}$ architectures of the future", ATZ Elektron Worldw 9(04), 40-45, 2014.

[13] J. Kloetzl, D. Gerling, "Stability in automotive power nets: Definitions, algorithms and experimental validation", in 14th European Conference on Power Electronics and Applications, Birmingham England, 2011.

[14] T. Cleff, Deskriptive Statistik und moderne Datenanalyse: Eine computergestuetzte Einfuehrung mit Excel, PASW (SPSS) und STATA, Gabler Verlag, 2012.

[15] EUROPEAN PARLIAMENT AND OF THE COUNCIL of 11 March 2014 amending Regulation (EC) No 443/2009 to define the modalities for reaching the 2020 target to reduce CO2 emissions from new passenger cars, Regulation (EC) No $443 / 2009$

[16] U. Tietge, S. Daz, P. Mock, J. German, A. Bandivadekar, N. Ligterink, "From Laboratory to Road: A 2016 Update of Official and Real-World Fuel Consumption and $\mathrm{CO} 2$ Values for Passenger Cars in Europe", International Council on Clean Transportation, 2016.

[17] A. Steward, A. Hope-Morley, P. Mock, and U. Tietge, "Quantifying the impact of real-world driving on total $\mathrm{CO} 2$ emissions from UK cars and vans", element energy, 2015.

[18] S. Pischinger, U. Seiffert, Vieweg Handbuch Kraftfahrzeugtechnik, Springer Vieweg, 2016.

[19] L. Brabetz, M. Ayeb, O. Baumgarten, "Tool-based Optimization of the Topology of an Electrical Distribution System (EDS)", SAE Int. J. Engines 9(3),2016.

[20] U. Dieckhoefer, V. Hoffmann, U. Hornfeck, "Decentralised Wiring System Architecture Power Distribution Next Generation", ATZ Elektron Worldw 11(01), 38-41, 2016. 